Abstract-Blackspotted rockfish (Sebastes melanostictus) and rougheye rockfish (S. aleutianus) are sympatric species found in the North Pacific Ocean. However, these species were not identified as separate taxa until the mid-2000s, and they remain difficult to differentiate in the field. These species are managed as a single mixed stock despite the fact that the North Pacific Fisheries Management Council rates them as Tier 3 species, meaning that an individual assessment including historical data is required for each. In this study, we developed a technique that distinguishes these species on the basis of otolith morphology and age, allowing both old and new collections to be identified to the correct species. Tissue samples and otoliths were collected from 1847 specimens during survey seasons in 2009 and 2013. Tissue samples were identified genetically to species by using the Sma 6 microsatellite locus. We used morphometrics, weight, and age from 859 otoliths to develop a logistic regression model that identified $97.3 \%$ of blackspotted rockfish and $86.2 \%$ of rougheye rockfish. Otolith shape analysis distinguishes rougheye rockfish and blackspotted rockfish and can allow for more focused management of these species.

Manuscript submitted 14 November 2018. Manuscript accepted 15 August 2019. Fish. Bull. 117:234-244 (2019). Online publication date: 30 August 2019. doi: $10.7755 /$ FB.117.3.10

The views and opinions expressed or implied in this article are those of the author (or authors) and do not necessarily reflect the position of the National Marine Fisheries Service, NOAA.

\title{
Using otolith morphometric analysis to improve species discrimination of blackspotted rockfish (Sebastes melanostictus) and rougheye rockfish (S. aleutianus)
}

\author{
Jeremy P. Harris (contact author) ${ }^{1}$ \\ Charles Hutchinson ${ }^{1}$ \\ Sharon Wildes ${ }^{2}$ \\ Email address for contact author: jeremy.harris@noaa.gov \\ ${ }^{1}$ Alaska Fisheries Science Center \\ National Marine Fisheries Service, NOAA \\ 7600 Sand Point Way NE \\ Seattle, Washington 98115-6349 \\ ${ }^{2}$ Auke Bay Laboratories \\ Alaska Fisheries Science Center \\ National Marine Fisheries Service, NOAA \\ 17109 Point Lena Loop Road \\ Juneau, Alaska 99801
}

The blackspotted rockfish (Sebastes melanostictus) and rougheye rockfish (S. aleutianus) are 2 of the largest and longest-lived rockfish species found in the North Pacific Ocean. The distribution of blackspotted rockfish stretches along the western coasts of the United States and Canada from Northern California to the Gulf of Alaska and across the Aleutian Islands and North Pacific Ocean to as far as Japan. The rougheye rockfish ranges from California to the Aleutian Islands (Orr and Hawkins, 2008). They are 2 of 72 rockfish species found in the North Pacific Ocean (Love et al., 2002). Although not targeted, rougheye rockfish and blackspotted rockfish occur as incidental catches in several major fisheries in the Gulf of Alaska, Bering Sea, and Aleutian Islands. Their slow population growth and late maturation make them vulnerable to overfishing (Ormseth and Spencer, 2011). These species are sympatric throughout the waters of Alaska, the coasts of British Columbia, Canada, and the West Coast of the United States, and they have only subtle morphological differences (Orr and Hawkins, 2008). Difficulties in accurately identifying these species have complicated research into their life history and ecology. Although both species are managed as a mixed stock at present, separation of the stock into individual species would be a major improvement in future assessments (Hicks et al., 2014; Shotwell et al., 2017).

Jordan and Evermann (1898) first described $S$. aleutianus, but it was not until 36 years later that Matsubara (1934) described a similar species, S. melanostictus. However, subsequent researchers reexamined the issue and found only 1 species with significant variation in body coloration (Barsukov, 1970; Kanayama and Kitagawa, 1982). A series of recent projects has since noted a genetic split within the species $S$. aleutianus, first on the basis of protein allozymes (Seeb, 1986; Hawkins et al., 2005) and subsequently by using mitochondrial DNA and microsatellites (Gharrett et al., 2005; Gharrett 
et al., 2006). In this research, the 2 species, which were referred to as Type I and Type II, have a fixed difference at the Sma6 microsatellite locus (Gharrett et al., 2005). Orr and Hawkins (2008) subsequently resurrected S. melanostictus for the blackspotted rockfish following a detailed morphological study. Orr and Hawkins (2008) also developed a discriminant model for identifying the 2 species with $97.8 \%$ total accuracy. Unfortunately, this method relies on careful caliper measurements of several morphological features, such as the gill rakers, dorsal spines, and pelvic fin rays. As such, this method has not been widely adopted for use with large-scale stock assessment surveys, and a quick and accurate method for distinguishing these species in the field remains elusive.

At sea, blackspotted rockfish can often be distinguished by black markings on the body, but these spots vary in number and intensity. Rougheye rockfish often have some minor spotting or dark coloration, such that there is considerable overlap in the color patterns of the species. Experienced field scientists can separate them with a moderate level of accuracy, but fishery observers and other personnel do not attempt to identify these species. The genus Sebastes has been found to have several cryptic species of similar appearance, but they have different habitat preferences and require different management measures (Hyde et al., 2008). Consequently, in some areas the fishery catch is predominantly blackspotted rockfish (Orr and Hawkins, 2008). If the catch is not evenly distributed, managing these species jointly runs the risk of causing detrimental effects to the more vulnerable population (Hawkins et al., 2005).

Otoliths are found as 3 paired sets of calcium carbonate structures in the inner ear of teleost fish species and function in hearing, balance, and orientation. In rockfish species, the sagittae are the largest of the otoliths and are most frequently collected for age determination. Age estimates are obtained by examining sectioned otoliths under a microscope, and ages obtained this way have been validated by using radiometric dating in a number of species (Hutchinson et al., 2007; Kastelle et al., 2008). Because otoliths from different populations may have unique shapes, the analysis of otolith data is a popular method for distinguishing similar species (Sadighzadeh et al., 2012) or different stocks within a species (Campana and Casselman, 1993; Hicks et al., 2003).

The purpose of this study was to develop a mathematical method that accurately separates the rougheye and blackspotted rockfish species on the basis of their otolith morphometrics and other data that are collected in the biennial fisheryindependent surveys conducted by the NOAA Alaska Fisheries Science Center (AFSC) in the Gulf of Alaska. Because diagnostic genetic markers have been developed (Gharrett et al., 2005), it is possible to correctly identify a specimen to species and to use these genetically identified specimens to construct and validate a discrimination method based on otolith morphology. This model will be used to separate the 2 species in AFSC fishery-dependent collections and to verify field identifications made on stock assessment surveys. An otolith-based discrimination method would give scientists access to over 30 years of AFSC archived otolith collections that were not separated by species until 2006 and would greatly increase the data for each species.

\section{Materials and methods}

\section{Sampling}

Otoliths were collected from rougheye rockfish and blackspotted rockfish sampled from the Gulf of Alaska in the summers of 2009 and 2013 during AFSC survey cruises on contracted fishing vessels (Fig. 1). During 2009 and 2013, AFSC scientists collected 945 and 902 fish, respectively. At the time of capture, each sampled rockfish was measured and weighed, its sex was determined, and its otoliths were removed and stored in 50\% glycerol-thymol solution. Fin clips were taken from each fish and stored in $20 \%$ dimethyl sulfoxide and 80\% 0.25-M EDTA solution.

\section{Genetic analysis}

Fin clips were sent to the AFSC Auke Bay Laboratories in Juneau, Alaska, for genetic analysis. These samples were genotyped according to the methods published in Wimberger et al. (1999). The Sma6 locus has been shown to clearly delineate rougheye and blackspotted rockfish species, with each species homozygous having a unique allele in more than $99.7 \%$ of all specimens (Gharrett et al., 2005). The field identifications were compared with the genetic

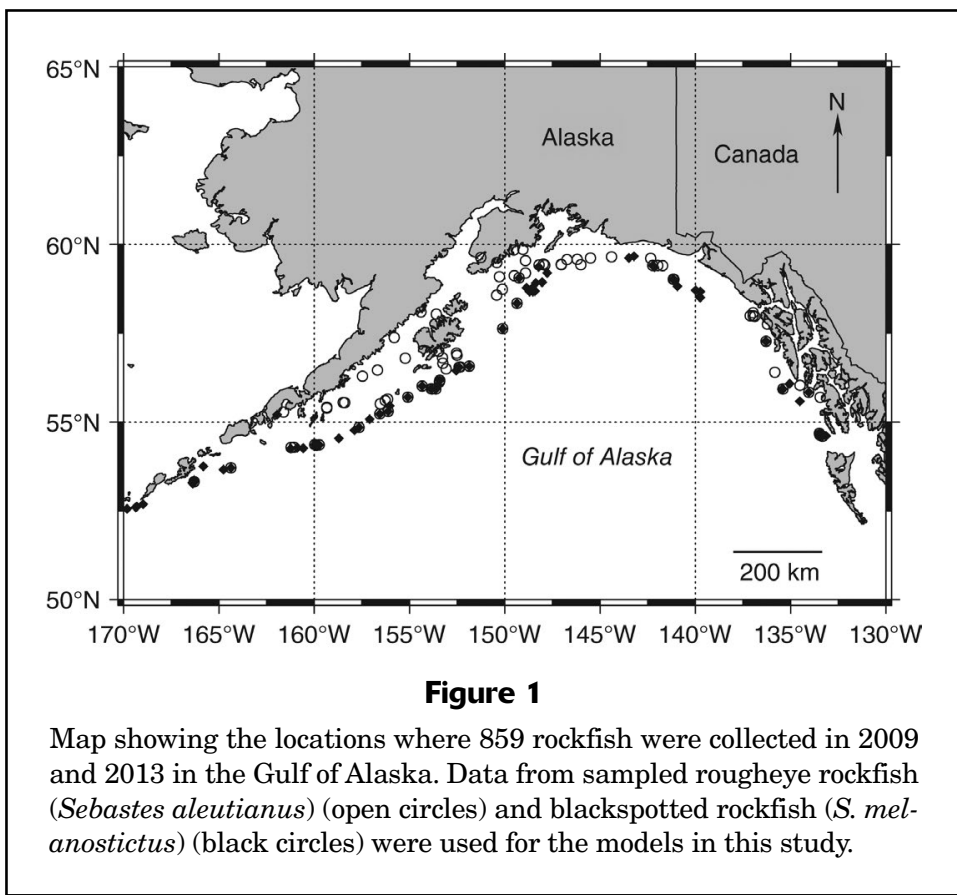


identification to estimate the accuracy of survey personnel in field conditions. Specimens that could not be conclusively genetically identified were removed from further analysis.

\section{Measurements and statistical analysis}

Otoliths were prepared for measurements by blotting them dry and placing them under a dissecting microscope. The otoliths were viewed distal side facing up on a black background at a magnification of $6.3 \times$. Image-Pro Plus ${ }^{1}$ software (vers. 7; Media Cybernetics, Inc., Rockville, MD) was used to capture otolith images, calculate each otolith's area, perimeter, Feret length, and Feret width, and determine the length and width of each otolith from lines intersecting at the center of the otolith core (major and minor axes) (Tuset et al., 2003). Otolith weight was taken to the nearest thousandth of a gram by using a Sartorius milligram balance (Sartorius AG, Göttingen, Germany). Measurements were imported to Microsoft Excel 2010 (Microsoft Corp., Redmond, WA). The first 72 blackspotted rockfish and 90 rougheye rockfish were tested for asymmetry between their left and right otoliths. This test found no significant differences (multivariate analysis of variance: $P=0.122$ ), and during the remainder of the study no distinction was made between left or right otoliths. Otolith age was read by scientists from the AFSC Age and Growth Program in accordance with established protocols (Matta and Kimura, 2012).

Initial analysis of the data indicated potential differences between the species in terms of otolith size versus age. The significance of these trends in otolith shape or otolith weight were compared in each species through regression analysis of the form shown in this equation:

$$
\begin{aligned}
\text { Variable }= & \text { Intercept }+\beta_{1} \text { Species }+\beta_{2} \log _{10} \text { Age } \\
& +\beta_{3} \text { Species } \times \log _{10} \text { Age }+\varepsilon,
\end{aligned}
$$

where $\beta=$ the estimated coefficient for each model term; Species $=$ the genetic identification for each specimen as a categorical variable;

$\log _{10}$ Age $=$ the log-transformed age of the specimen; and $\varepsilon=$ an error term with a normal distribution.

Seven variables were modeled: area, perimeter, otolith length, otolith width, major axis length, minor axis length, and otolith weight. A log transformation was applied to otolith ages to render these comparisons as a linear relationship. A $t$-test with a Bonferroni correction was applied to judge the significance of all regression parameters. Additionally, the von Bertalanffy growth function (von Bertalanffy, 1938) was used to model the relationship of age to fork length:

$$
\text { Fork length }=L_{\infty}\left(1-e^{-\mathrm{K}\left(\text { Age }-\mathrm{t}_{0}\right)}\right)
$$

where $L_{\infty}=$ mean asymptotic length;

$K=$ the growth coefficient; and

$t_{0}=$ the time or age when mean length was zero.

\footnotetext{
${ }^{1}$ Mention of trade names or commercial companies is for identification purposes only and does not imply endorsement by the National Marine Fisheries Service, NOAA.
}

Linear models were fit by using the $\mathrm{lm}$ function in statistical software R (vers. 3.3.3; R Core Team, 2017), and parameters of the the von Bertalanffy growth function were estimated by using the nls function in $R$.

Logistic regression is a standard statistical tool that can be used to assign classification probabilities on the basis of a variety of parameters (McCullagh and Nelder, 1989). For otolith morphometrics, the function calculates a probability $(P)$ between 0 and 1 that corresponds to the likelihood that a given otolith is from a rougheye rockfish and probability $(1-P)$ that the otolith is from a blackspotted rockfish. The advantage of this method over other classification procedures (e.g., discriminant analysis) is that it is robust to deviations from normality and heteroscedasticity that are assumed for most other statistical models and is equally effective given a large sample size (McCullagh and Nelder, 1989). Growth-related differences in otolith measurements were accounted for by including age as an interaction for each variable in the model. The model contains 9 predictor variables: otolith area, otolith perimeter, otolith major axis length, otolith minor axis length, otolith length, otolith width, otolith weight, fish fork length, and fish $\log _{10}$-transformed age. The model also contains 8 interactions with $\log _{10}$-transformed age. Here is its abbreviated form:

$$
\operatorname{logit}\left(P_{\mathrm{i}}\right)=\ln \left(\frac{P_{\mathrm{i}}}{1-P_{\mathrm{i}}}\right)=\text { Intercept }+\beta_{\mathrm{j}}\left[X_{\mathrm{ij}}\right]+\varepsilon_{\mathrm{i}}
$$

where $P_{\mathrm{i}}=$ probability for specimen $i$;

$X_{\mathrm{ij}}=$ the matrix of $j$ predictor variables, including interactions, for specimen $i$;

$\beta_{\mathrm{j}}=$ the regression coefficient for each $j$ predictor variable; and

$\varepsilon_{\mathrm{i}}=$ an error term with a binomial distribution for specimen $i$.

Nonsignificant parameters were removed by using a stepwise backward elimination algorithm with Aikake information criterion (AIC). In addition to probabilities, the standard error of a prediction can be calculated on the basis of the linear combination of the standard errors in the parameter estimates. In this study, this standard error was used to calculate the $95 \%$ prediction interval around each specimen, and only specimens whose prediction interval did not cross the 0.5 threshold were classified as rougheye or blackspotted. Other specimens were assigned to an uncertain category, reflecting the fact that their prediction interval was not confined to a single species. This step removed specimens that may have been too close to call and improved the specificity of the model's predictions. This model was fit by using the glm function in $\mathrm{R}$.

The practical validity of a classification model is best determined by examining its accuracy when given new data. With this in mind, we divided the data collected during surveys in the 2 years into a training data set and a second validation or testing data set (Table 1). Of the 945 specimens in the sample from 2009, 738 fish were included in the actual study. Specimens were excluded because they 


\section{Table 1}

Division of data from blackspotted rockfish (Sebastes melanostictus) and rougheye rockfish (S. aleutianus) collected in the Gulf of Alaska in 2009 and 2013 into the 2 data sets used to construct and validate the logistic regression model. The model parameters were fit by using specimens from the training data set and then tested against a new set of specimens in the testing data set. The training data set includes 638 specimens, all from 2009, and the testing data set includes 221 specimens from both 2009 and 2013.

\begin{tabular}{lcrrr}
\hline & & \multicolumn{3}{c}{ Number of specimens } \\
\cline { 3 - 5 } Species & Year & $\begin{array}{l}\text { Training } \\
\text { data set }\end{array}$ & $\begin{array}{c}\text { Testing } \\
\text { data set }\end{array}$ & Total \\
\hline Blackspotted & 2009 & 434 & 50 & 484 \\
rockfish & 2013 & 0 & 62 & 62 \\
Rougheye & 2009 & 204 & 50 & 254 \\
rockfish & 2013 & 0 & 59 & 59 \\
& Total & 638 & 221 & 859 \\
& & & & \\
\hline
\end{tabular}

could not be genetically identified to species or because the corresponding otoliths were damaged and could not be measured. Of the fish used in the study, 50 specimens from each species were randomly assigned to the testing data set, and the remaining 638 fish were used to construct and fit the logistic regression function. Not all of the 902 specimens from the survey conducted in 2013 were necessary for an adequate test; therefore, 121 fish were randomly chosen and they were included in the testing data set. Overall, the training and testing sets covered similar ranges of age and length values, and the training and testing sets had similar mean ages and lengths (Table 2). In the testing data set, the predicted species of each otolith was compared with the genetically determined identity to yield the accuracy of this classification method.

This method relies heavily on otolith age to help discriminate between the blackspotted and rougheye rockfish species, but otolith age is typically more prone to measurement error than standard methods. Furthermore, these species frequently attain very old ages and are among the most difficult to read. Therefore, we simulated the potential effect of errors in the age reading process by generating a false age and using that age to estimate new classification probabilities. This simulation looks at 2 types of errors: bias and random noise. Bias is a systematic tendency to age an otolith higher or lower than its true age. With a $-10 \%$ bias, a 10 -year-old fish would be evaluated as if it were a 9 years old, and a 100-year-old fish would be evaluated as if it were 90 years old. Random noise was simulated by drawing from a normal distribution defined by the age and a coefficient of variation (CV) (standard deviation $[\mathrm{SD}] /$ mean). Hence, a 10 -year-old fish with a CV of 0.1 will have its age adjusted in each simulation run by an amount drawn from a normal distribution with an SD of 1 , and an SD of 10 would be used for a 100-year-old fish. These types of errors are combined to produce a simulated age by using this equation:

$$
\begin{gathered}
\text { New Age } \sim N(\mu=\text { MeasuredAge }(1+\text { bias }), \\
\sigma=\text { MeasuredAge } \times C V),
\end{gathered}
$$

where $N$ is the normal distribution with the mean equal to $\mu$ and the standard deviation equal to $\sigma$. This process was repeated 5000 times for each combination of error and bias, with the average classification accuracy measured for each run. All statistical analyses for this simulation were carried out by using $R$.

\section{Results}

\section{Genetics}

The results of the genetic analysis from the data collected during the survey in 2009 show that field identification accuracy was $92 \%$ for blackspotted rockfish and $66 \%$ for rougheye rockfish. Out of 945 samples, 540 fish were genetically identified as blackspotted rockfish and 318 fish were identified as rougheye rockfish. Additionally,

Table 2

Summary statistics for specimens of blackspotted rockfish (Sebastes melanostictus) and rougheye rockfish (S. aleutianus) sampled for the training data set used to construct the logistic regression model and for the testing data set used to validate the model's accuracy. Specimens were collected in the Gulf of Alaska in 2009 and 2013. All lengths are fork lengths in millimeters, and all ages are

\begin{tabular}{|c|c|c|c|c|c|c|c|c|}
\hline \multirow[b]{2}{*}{ Species } & \multirow[b]{2}{*}{ Data set } & \multirow[b]{2}{*}{$n$} & \multicolumn{3}{|c|}{ Length } & \multicolumn{3}{|c|}{ Age } \\
\hline & & & Min. & Mean & Max. & Min. & Mean & Max. \\
\hline \multirow[t]{2}{*}{ Blackspotted rockfish } & Training & 434 & 70 & 355 & 570 & 2 & 22 & 113 \\
\hline & Testing & 112 & 130 & 348 & 540 & 3 & 22 & 103 \\
\hline \multirow[t]{2}{*}{ Rougheye rockfish } & Training & 204 & 130 & 396 & 670 & 3 & 20 & 135 \\
\hline & Testing & 109 & 120 & 371 & 730 & 3 & 17 & 83 \\
\hline
\end{tabular}
in years. $n=$ number of specimens. 
17 specimens were heterozygous at the $S m a 6$ locus and were identified as hybrids, and 70 samples were degraded or otherwise produced inconclusive results. The data collected in 2013 indicate an improvement to $94 \%$ and $68 \%$ accuracy in field identifications of blackspotted rockfish and rougheye rockfish, respectively. Of the 902 specimens, 428 were blackspotted rockfish, 429 were rougheye rockfish, 8 were Sma6 hybrids, and 37 fish could not be identified to species.

\section{Multivariate regression and length at age}

Across all measurements examined, otoliths of rougheye rockfish tended to be a larger size for a given age than blackspotted rockfish, as shown by bivariate plots (Fig. 2). This pattern manifests as a small but significant differences in the initial size of otoliths and in the rate at which these structures grow with age. According to all 7 of the parameters, otoliths of rougheye rockfish are greater beginning in the first few years of life, as evidenced by a significant species effect on the intercept (Table 3). A more varied response is observed as the fish grow, with some characteristics like otolith length, major axis length, and perimeter tending to converge over time (Fig. 2). By comparison, otolith area becomes even more divergent. In most cases, the difference in slopes between the species is not significant (Table 3), indicating that most of the size difference in rougheye rockfish occurs in the early years of life. A very similar dynamic is observed in the von Bertalanffy growth curves (Fig. 3, Table 4). Rougheye rockfish have a much higher rate of growth early in life, leading to a significant gap in the length at age between the 2 species.

\section{Classification success}

Logistic regression found that several otolith parameters and age interactions were predictive of species between these 2 rockfish species. Several of the predictors used in this model are highly correlated; however, removal of these collinear predictors resulted in a worse fit to the data as measured by AIC. Removing collinear predictors had little effect on discrimination accuracy. Therefore, only nonsignificant parameters that did not increase AIC were eliminated from the final model. The full model that includes all 8 parameters and 7 interactions had an AIC of 143.35, and the reduced model that includes all 8 parameters and 2 interactions had an
AIC of 139.93 (Table 5). Of the 638 specimens used to build the logistic regression, $94.7 \%$ of 434 blackspotted rockfish and $88.2 \%$ of 204 rougheye rockfish could be correctly identified, once uncertain cases were removed (Table 6). However, the best test of a classification method is its accuracy when confronted with new data. When used to classify 221 specimens from the testing data set, it was successful for $97.3 \%$ of 112 blackspotted rockfish and $86.2 \%$ of 109 rougheye rockfish (Fig. 4, Table 6). Overall, 11 of the 221 fish are classified as uncertain because their prediction intervals indicate both possibilities of species idenfitication are reasonably likely. Of these 11 specimens, 5 fish would have been assigned to the incorrect species, a result that would almost double the total number of misidentifications. When uncertain cases were excluded, only $0.9 \%$ of blackspotted rockfish and $5.5 \%$ of rougheye rockfish were misidentified (Table 6).

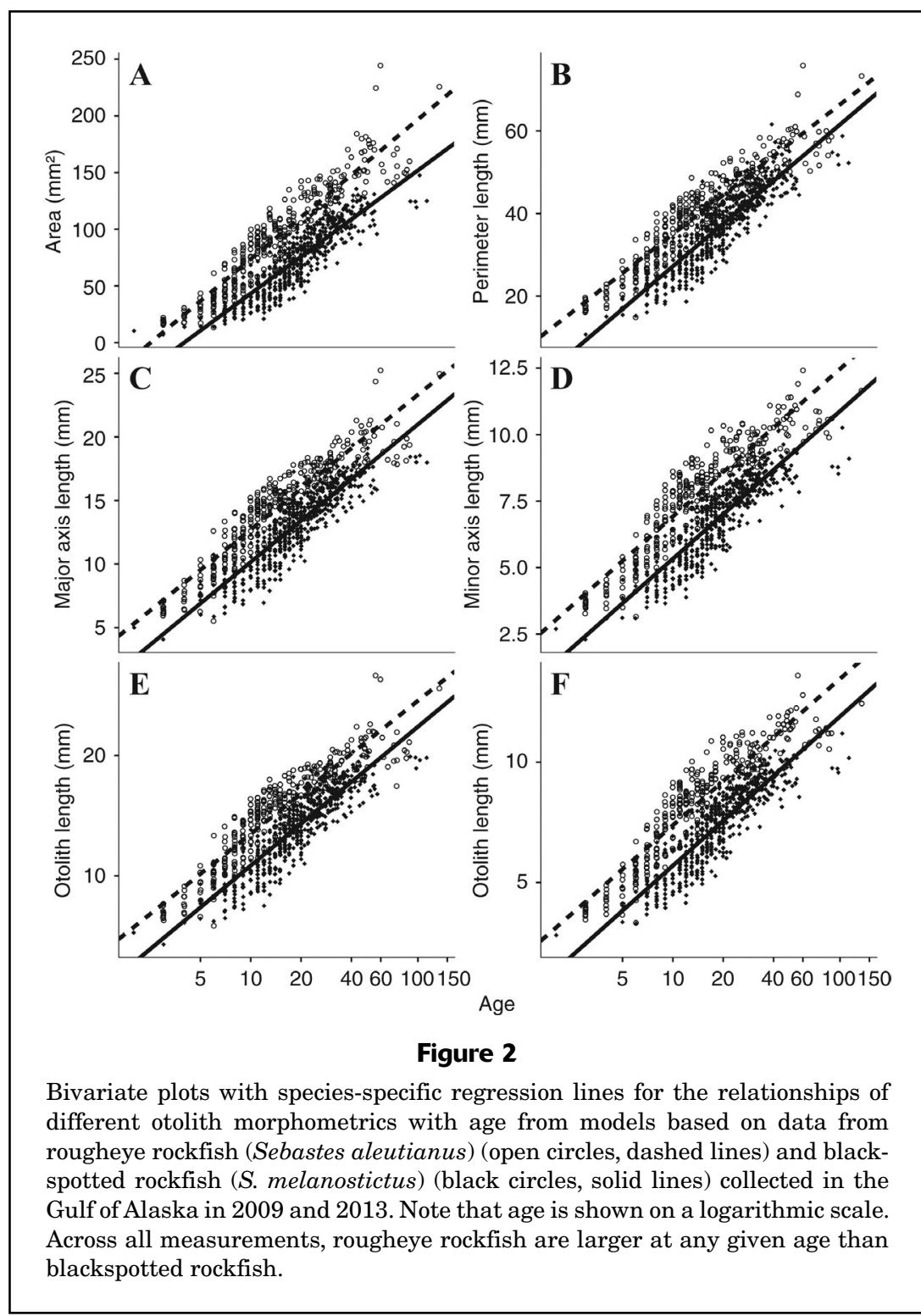




\section{Table 3}

Regression statistics for each of 6 morphometric parameters and otolith weight. Each set of 2 rows provides the parameter versus $\log _{10}$-transformed age in blackspotted rockfish (Sebastes melanostictus) and rougheye rockfish (S. aleutianus), as well as the $t$-statistics and $P$-values used to examine whether the species have different slopes or intercepts. Because multiple tests were conducted, a Bonferroni correction was applied such that differences are considered significant only if $P<0.003$. Data used in the regression model are from specimens collected in the Gulf of Alaska in 2009 and 2013.

\begin{tabular}{llccccc}
\hline Otolith variable & Parameter & $\begin{array}{c}\text { Blackspotted } \\
\text { rockfish }\end{array}$ & $\begin{array}{c}\text { Rougheye } \\
\text { rockfish }\end{array}$ & Difference & $t$ & $P$ \\
\hline Area & Intercept & -65.1 & -49.2 & 15.9 & 3.61 & $<0.001$ \\
& Slope & 108.5 & 123.0 & 14.4 & 4.09 & $<0.001$ \\
Perimeter & Intercept & -7.11 & 3.67 & 10.78 & 8.30 & $<0.001$ \\
& Slope & 34.3 & 31.4 & -2.9 & -2.85 & 0.004 \\
Major axis length & Intercept & -0.66 & 2.13 & 2.79 & 6.46 & $<0.001$ \\
& Slope & 10.8 & 10.6 & -0.2 & -0.67 & 0.506 \\
Minor axis length & Intercept & -0.22 & 1.37 & 1.59 & 6.91 & $<0.001$ \\
& Slope & 5.55 & 5.55 & -0.005 & -0.004 & 0.979 \\
Otolith length & Intercept & -0.71 & 2.41 & 3.12 & 6.68 & $<0.001$ \\
& Slope & 11.56 & 11.08 & -0.48 & -1.28 & 0.202 \\
Otolith width & Intercept & -0.50 & 1.30 & 1.80 & 7.11 & $<0.001$ \\
& Slope & 6.20 & 6.08 & -0.117 & -0.58 & 0.563 \\
Otolith weight & Intercept & -0.357 & -0.456 & -0.099 & -4.49 & $<0.001$ \\
& Slope & 0.463 & 0.695 & 0.232 & 13.15 & $<0.001$ \\
& & & & & & \\
\end{tabular}

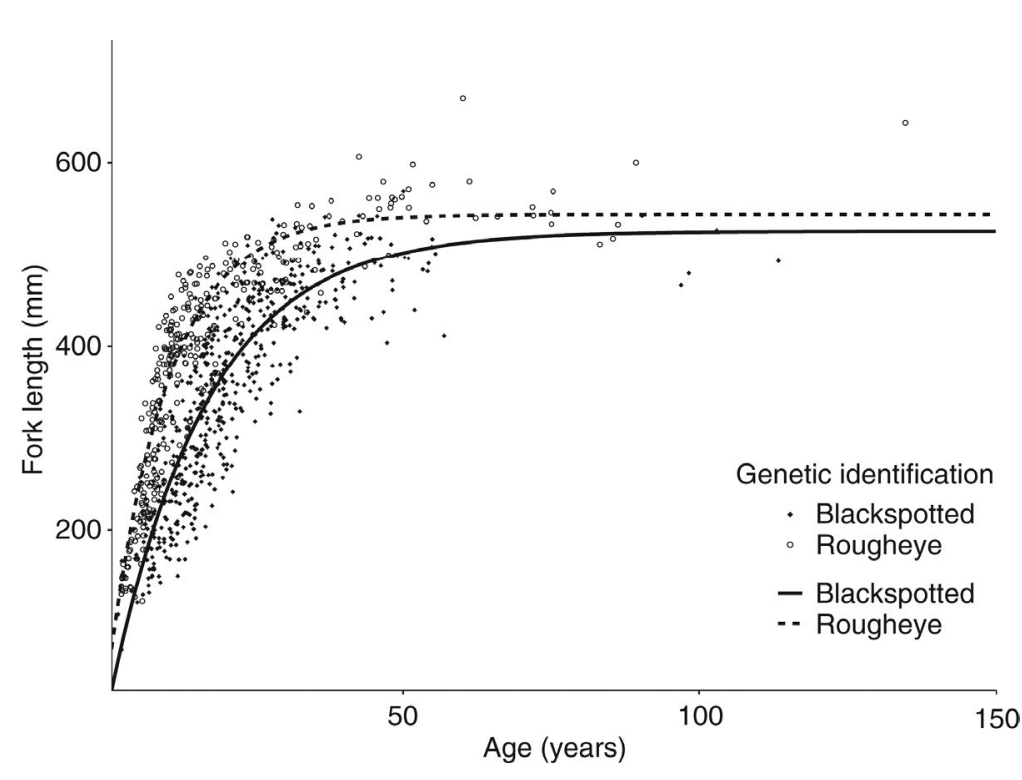

Figure 3

Estimated von Bertalanffy growth curves for rougheye rockfish (Sebastes aleutianus) (open circles, dashed line) and blackspotted rockfish (S. melanostictus) (black circles, solid line). Data used in the growth model come from specimens collected in the Gulf of Alaska in 2009 and 2013. Similar to the pattern predicted for otolith parameters, rougheye rockfish grow at a substantially faster rate and achieve a greater length at age than blackspotted rockfish.

\section{Simulation}

The classification process was found to be robust with respect to moderate errors in the age assigned to each specimen through otolith analysis (Fig. 5). Classification accuracy averaged across both species remained above $90 \%$ when bias and CV were each less than $10 \%$. Random errors in the aging process (represented by $\mathrm{CV}$ ) generally were not a severe concern unless they were particularly strong with overall accuracy exceeding $80 \%$ even with a $\mathrm{CV}$ of 0.2 . In contrast, classification accuracy indicates a strong response to directional bias and particularly suffers if the assigned ages are too low.

\section{Discussion}

In this study, otolith data, fork length, and age were sufficient to correctly identify $97 \%$ of blackspotted rockfish and $86 \%$ of rougheye rockfish (Table 6 ). This model's accuracy provides a slight improvement compared with the $92-94 \%$ of blackspotted rockfish 


\section{Table 4}

Results for parameters of the von Bertalanffy growth function for blackspotted rockfish (Sebastes melanostictus) and rougheye rockfish (S. aleutianus) collected in the Gulf of Alaska in 2009 and 2013. The parameters are the mean asymptotic length $\left(L_{\infty}\right)$, the growth coefficient $(K)$ and the time or age when mean length was zero $\left(t_{0}\right) . n=$ number of specimens.

\begin{tabular}{lcc}
\hline Parameter & $\begin{array}{c}\text { Blackspotted } \\
\text { rockfish }\end{array}$ & $\begin{array}{c}\text { Rougheye } \\
\text { rockfish }\end{array}$ \\
\hline$n$ & 546 & 313 \\
$L_{\infty}$ & $526 \mathrm{~mm}$ & $544 \mathrm{~mm}$ \\
$K$ & 0.062 & 0.102 \\
$t_{0}$ & 0.2 & -0.36 \\
\hline
\end{tabular}

that are correctly identified in the field. However, the model substantially improves identification of rougheye rockfish, for which field identifications are only $66-68 \%$ accurate. The results of a more recent study of field identifications from the season in 2015 indicate $75 \%$ accuracy (Shotwell et al., 2017), but this level of accuracy is still significantly worse than the results obtained in this study.

Most studies of this kind will assign a species to all specimens, even if the model indicates a high degree of uncertainty. We recommend a more conservative

\section{Table 5}

Regression coefficients for the final form of the logistic regression model following stepwise elimination of parameters. Data used in the regression model are from blackspotted rockfish (Sebastes melanostictus) and rougheye rockfish (S. aleutianus) collected in the Gulf of Alaska in 2009. After stepwise elimination, all remaining parameters were significantly different from zero.

\begin{tabular}{|c|c|c|c|c|}
\hline Parameter & Coefficient & Error & $z$-score & $P$ \\
\hline Intercept & -18.92 & 5.37 & -3.53 & $<0.01$ \\
\hline Area & 1.07 & 0.25 & 4.29 & $<0.01$ \\
\hline Perimeter & 2.88 & 0.64 & 4.51 & $<0.01$ \\
\hline Minor axis length & 7.36 & 3.50 & 2.10 & 0.04 \\
\hline Otolith width & -7.96 & 3.12 & -2.55 & $<0.01$ \\
\hline Otolith length & -3.23 & 1.06 & -3.06 & $<0.01$ \\
\hline Otolith weight & -174.87 & 59.03 & -2.96 & $<0.01$ \\
\hline Fork length & -0.08 & 0.02 & -4.60 & $<0.01$ \\
\hline $\log _{10}($ Age $)$ & 32.74 & 10.82 & 3.03 & $<0.01$ \\
\hline $\begin{array}{l}\text { Perimeter } \times \\
\log _{10}(\text { Age })\end{array}$ & -2.81 & 0.55 & -5.15 & $<0.01$ \\
\hline $\begin{array}{l}\text { Otolith weight } \times \\
\log _{10}(\text { Age })\end{array}$ & 133.79 & 33.78 & 3.96 & $<0.01$ \\
\hline
\end{tabular}

approach as a further defense against errors imposed by the process of otolith age determination. Our method trades a decrease in misclassifications (improved specificity) for the cost of fewer correct classifications

\section{Table 6}

Results of species classification from the logistic regression model comparing the agreement between the genetic identification and the species predicted by the model constructed and validated with data for blackspotted rockfish (Sebastes melanostictus) and rougheye rockfish (S. aleutianus) collected in the Gulf of Alaska in 2009 and 2013. Data are from the training data set used to fit the regression model and from the testing data set created when the regression model was used on new data. Values in the left columns provide the results when all specimens were classified and those in the right columns indicate the effect of removing specimens classified as uncertain. $n=$ number of specimens; ID=identification.

\begin{tabular}{|c|c|c|c|c|c|}
\hline \multirow[b]{3}{*}{$\begin{array}{l}\text { Data set for } \\
\text { genetic ID }\end{array}$} & \multicolumn{5}{|c|}{ Number of specimens (successful ID [\%]) } \\
\hline & \multicolumn{2}{|c|}{ Model ID (all classified) } & \multicolumn{3}{|c|}{ Model ID (uncertain cases removed) } \\
\hline & $\begin{array}{l}\text { Blackspotted } \\
\text { rockfish }\end{array}$ & $\begin{array}{l}\text { Rougheye } \\
\text { rockfish }\end{array}$ & $\begin{array}{l}\text { Blackspotted } \\
\text { rockfish }\end{array}$ & $\begin{array}{l}\text { Rougheye } \\
\text { rockfish }\end{array}$ & Uncertain \\
\hline \multicolumn{6}{|l|}{ Training data set } \\
\hline $\begin{array}{l}\text { Blackspotted rockfish } \\
n=434\end{array}$ & $\begin{array}{c}424 \\
(97.6 \%)\end{array}$ & $\begin{array}{c}10 \\
(2.3 \%)\end{array}$ & $\begin{array}{c}411 \\
(94.7 \%)\end{array}$ & $\begin{array}{c}5 \\
(1.2 \%)\end{array}$ & $\begin{array}{c}18 \\
(4.1 \%)\end{array}$ \\
\hline $\begin{array}{l}\text { Rougheye rockfish } \\
n=204\end{array}$ & $\begin{array}{c}11 \\
(5.4 \%)\end{array}$ & $\begin{array}{c}193 \\
(94.6 \%)\end{array}$ & $\begin{array}{c}7 \\
(3.4 \%)\end{array}$ & $\begin{array}{c}180 \\
(88.2 \%)\end{array}$ & $\begin{array}{c}17 \\
(8.3 \%)\end{array}$ \\
\hline \multicolumn{6}{|l|}{ Testing data set } \\
\hline $\begin{array}{l}\text { Blackspotted rockfish } \\
n=112\end{array}$ & $\begin{array}{c}110 \\
(98.2 \%)\end{array}$ & $\begin{array}{c}2 \\
(1.8 \%)\end{array}$ & $\begin{array}{c}109 \\
(97.3 \%)\end{array}$ & $\begin{array}{c}1 \\
(0.9 \%)\end{array}$ & $\begin{array}{c}2 \\
(1.8 \%)\end{array}$ \\
\hline $\begin{array}{l}\text { Rougheye rockfish } \\
n=109\end{array}$ & $\begin{array}{c}10 \\
(9.2 \%)\end{array}$ & $\begin{array}{c}99 \\
(90.8 \%)\end{array}$ & $\begin{array}{c}6 \\
(5.5 \%)\end{array}$ & $\begin{array}{c}94 \\
(86.2 \%)\end{array}$ & $\begin{array}{c}9 \\
(8.2 \%)\end{array}$ \\
\hline
\end{tabular}




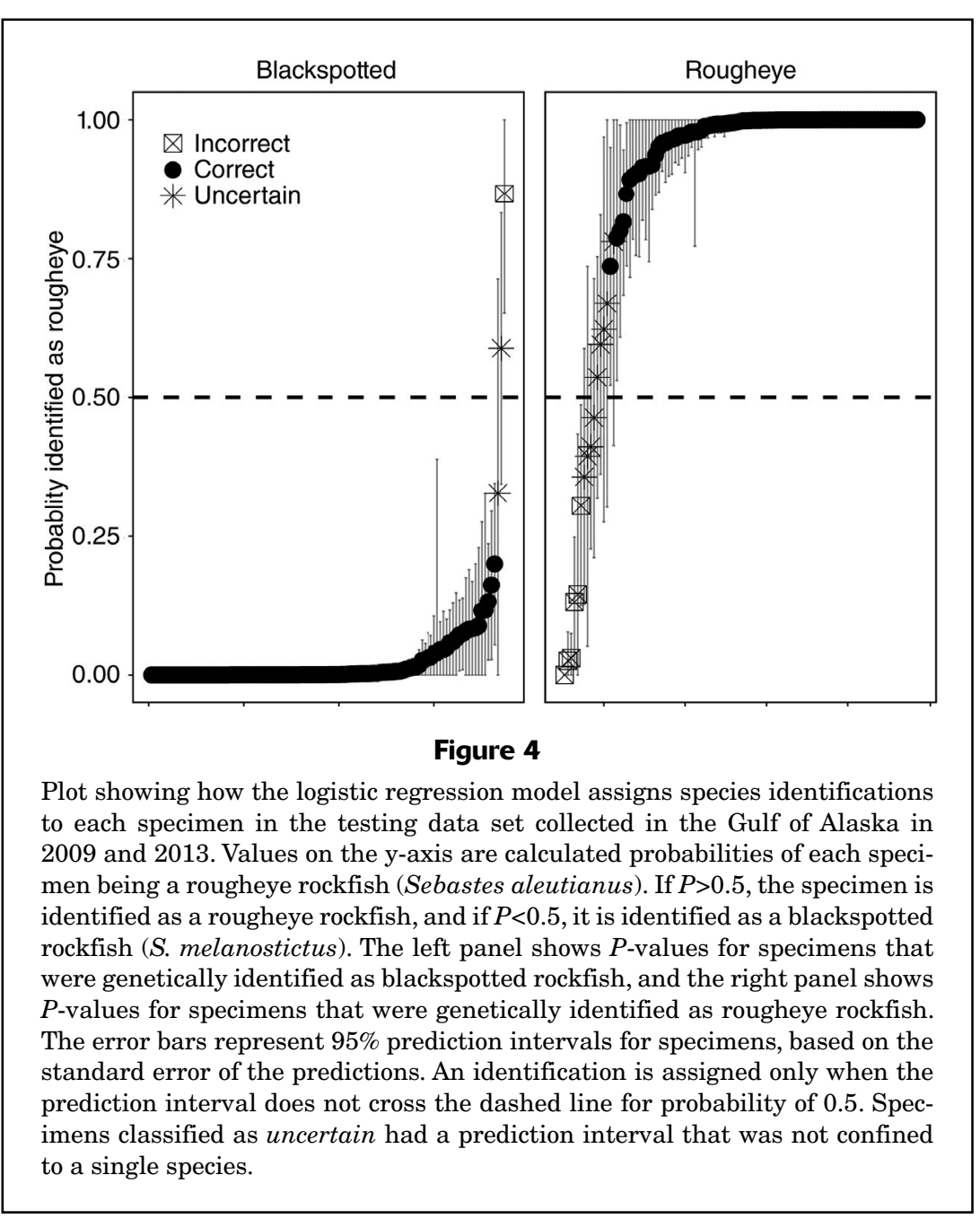

specimens is unlikely to have caused a bias in this data set.

A key finding in this study is the importance of age in distinguishing the 2 species. A common practice in morphometric studies is to standardize all fish to a set size, usually determined by standard or fork length (Campana, 1999; Lleonart et al., 2000). For this study, age was included as an interaction effect with the other predictors, allowing the model to account for it directly. In this study, we observed that almost no difference existed between the species when their otolith measurements were compared with fork length, but a clear separation in the growth patterns emerged when age was considered (Figs. 2 and 3). Our findings are consistent with a growing understanding that, despite their similarities, the rougheye and blackspotted rockfish species have different rates of growth (Conrath, 2017; Shotwell et al., 2017) and specifically that rougheye rockfish grow faster and attain a larger size at age. The von Bertalanffy growth parameters obtained in this study indicate a strong divergence between the 2 species (Table 4). Given our findings, it is possible that using age alongside length or body size may help resolve other problems of difficult stock or species discrimination. Including measurements such as fork length and age into a model as an interaction carries the fewest overall assumptions, makes full use

(decreased accuracy) caused by discarding a number of otoliths (approximately 5\% overall) that are ruled uncertain on the basis of the estimated error around each prediction. Likewise, if the uncertain specimens had been classified, overall accuracy would have increased but the number of misidentifications would have increased as well (Table 6). The logistic regression method developed in this study allows the use of an algorithm to determine when specimens are too difficult or atypical to identify. Removal of the uncertain otoliths led to high specificity, with less than $5 \%$ of specimens misidentified. With both high accuracy and high specificity, this method ensures the highest quality data are available for use in managing the populations of these species. In contrast, if a simpler method that attempts to identify all specimens is used, some additional specimens will be correctly identified if they fall on the correct side of the threshold of $P=0.5$ (Fig. 4), but misidentifications double to as much as $9-10 \%$ in rougheye rockfish. In this study, no apparent pattern was observed with uncertain specimens with respect to age or location, meaning that the exclusion of uncertain of all available information, and allows the difference in growth rate to inform the results and improve the predictions of the model.

The most significant disadvantage of this method is that reading the ages of otoliths is time consuming, and each specimen would not receive a final species identification for several weeks or months. Although measurements of age have a higher error than other data, the results of our simulations indicate that moderate age determination errors, consistent with commonly reported estimates, are unlikely to degrade the accuracy of this method. The AFSC reports an age determination $\mathrm{CV}$ of 0.08 for rougheye rockfish, meaning that otolith age readers tend to disagree by $8 \%$. In the simulation conducted in our study, the logistic regression model maintains high overall accuracy $(\approx 90 \%)$ in this simulation (Fig. 5). This method is somewhat more vulnerable to systematic bias in age estimates. The drop in classification accuracy from increasing directional bias is not greater than that from random noise, but it happens unevenly. The core observation on which this model is based is that otoliths of rougheye rockfish are larger and 


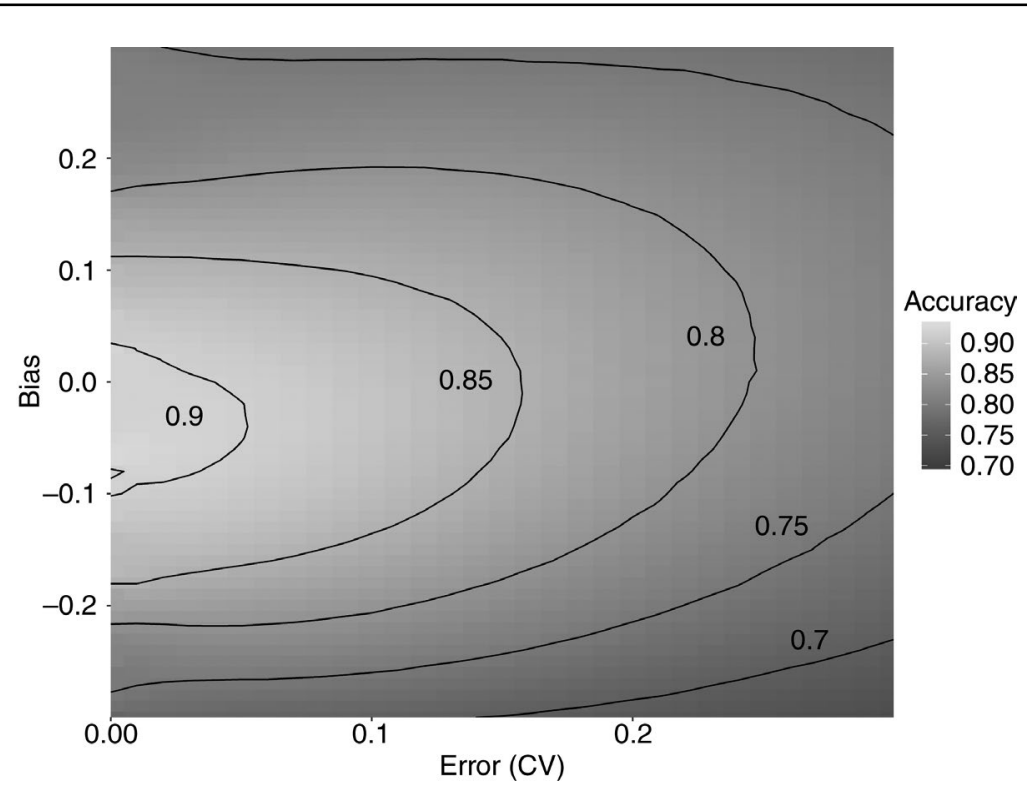

Figure 5

Heatmap showing the accuracy of the species prediction method used in this study, with simulated errors. Lighter shades of gray indicate higher accuracy. Contour lines highlight the gradual change in values of accuracy. Coefficients of variation $(\mathrm{CVs})$ on the $\mathrm{x}$-axis represent simulated random errors in the aging process, and values on the $y$-axis indicate bias in a specific positive or negative direction.

eastern Aleutian Islands, and in the southern Bering Sea. We have tried to account for any potential geographic and temporal differences by collecting specimens from different locations in the Gulf of Alaska (Fig. 1) and in 2 different years. The model was developed and fit by using data from 2009, but it was tested against additional data from 2009 as well as data from a second collection of specimens made in 2013. The model performed well with data from both years, with only $2-3 \%$ difference between years in overall accuracy. We think this result is a strong indication that attempts to apply this method in future years throughout the Gulf of Alaska and Bering Sea will be successful.

Considering the positive performance of this logistic regression model, we predict it will be useful to classify or reclassify historical otolith samples from mixed species catches. Applying these findings backward in time does rely on the assumption that the growth rates of these fish species in the present day are similar to those of the past and have not been altered by changes in climate, fishing, or other forces. However, given that both species have a rather

grow faster than otoliths of blackspotted rockfish. If ages are systematically biased upward, more fish will appear to be slower growing and the model will predict a greater number of blackspotted rockfish. Conversely, a bias toward lower ages will make specimens appear to be faster growing and will tend to predict more rougheye rockfish. With this in mind, it is imperative that the age determination process carefully police any nonrandom errors.

This model is not designed to identify hybrids or classify hybrids. Of the 1847 specimens that were genetically identified from the surveys conducted in 2009 and 2013, 25 (1.3\%) fish were hybrids at the Sma6 locus. With such a small sample, this study was unable to determine what potential effect these hybrids might have had on the accuracy of identifications. The best course of action may be to assume that hybrids represent a minor source of identification error. Furthermore, this model should not be expected to identify or remove miscellaneous rockfish species from a mixed sample of otoliths. All specimens must be correctly identified as part of the rougheye and blackspotted species complex in the field, and it will require that field personnel be adequately trained to identify other species.

All the specimens used in this study were collected from the Gulf of Alaska, but the rougheye and blackspotted rockfish species are found together off the western coasts of the United States and Canada, in the long life span, many of the fish in this study did experience those past environmental conditions. Many of the specimens collected are 30 years old or older, and the oldest is a 135-year-old rougheye rockfish with an estimated birth year of 1878. Errors for the model were not correlated with increasing age, meaning that the model was capable of assigning the correct species whether the majority of a fish's growth occurred in present day conditions or those of decades past. This is a promising indication that the model will be reliable for archived specimens going back at least 20-30 years, making it invaluable for establishing individual stock assessments for each species.

The rougheye rockfish and the blackspotted rockfish are assessed as a complex in a single statistical agestructured model that assumes equal age compositions, growth rates, and many other parameters (Shotwell et al., 2017). However, it has been observed that the spatial and depth distributions of the 2 species are different (Orr and Hawkins, 2008) and that rougheye rockfish appear to grow faster and mature earlier (Conrath, 2017). Although Conrath's findings are consistent with our observations of growth at age, her study did not confirm species identifications with genetics, raising the possibility that her estimates are skewed by misidentifications. In the future, our method will allow researchers to more confidently identify these species and arrive at more accurate estimates of important population parameters. New studies, 
along with disaggregating historically mixed samples, will allow for better estimates of age, growth, and abundance and will most likely lead to an improved assessment for each species and provide a long-term benefit to sustainable management.

\section{Acknowledgments}

We would like to thank everyone who assisted in collecting or archiving specimens during the surveys conducted in 2009 and 2013 in the Gulf of Alaska, especially J. Heifetz, who was instrumental in obtaining genetic samples paired to otoliths. We also thank the staff at the Auke Bay Laboratories for conducting all of the genetic tests. J. Orr and J. Heifetz provided much useful feedback on the initial manuscript, and we would like to thank the anonymous reviewers who provided many useful suggestions.

\section{Literature cited}

Barsukov, V. V.

1970. Specific structure of Sebastes genus in northern part of Pacific, with description of a new species. Dokl. Bot. Sci. 195:994-997.

Campana, S. E.

1999. Chemistry and composition of fish otoliths: pathways, mechanisms and applications. Mar. Ecol. Prog. Ser. 188:263-297. Crossref

Campana, S. E., and J. M. Casselman.

1993. Stock discrimination using otolith shape-analysis. Can. J. Fish. Aquat. Sci. 50:1062-1083. Crossref

Conrath, C. L.

2017. Maturity, spawning omission, and reproductive complexity of deepwater rockfish. Trans. Am. Fish. Soc. 146:495-507. Crossref

Gharrett, A. J., A. P. Matala, E. L. Peterson, A. K. Gray, Z. Z. Li, and J. Heifetz.

2005. Two genetically distinct forms of rougheye rockfish are different species. Trans. Am. Fish. Soc. 134:242-260. Crossref

Gharrett, A. J., C. W. Mecklenburg, L. W. Seeb, Z. Li, A. P. Matala,

A. K. Gray, and J. Heifetz.

2006. Do genetically distinct rougheye rockfish sibling species differ phenotypically? Trans. Am. Fish. Soc. 135:792800. Crossref

Hawkins, S. L., J. Heifetz, C. M. Kondzela, J. E. Pohl, R. L. Wilmot,

O. N. Katugin, and V. N. Tuponogov.

2005. Genetic variation of rougheye rockfish (Sebastes aleutianus) and shortraker rockfish (S. borealis) inferred from allozymes. Fish. Bull. 103:524-535.

Hicks, A. C., P. J. Smith, P. L. Horn, and D. J. Gilbert.

2003. Differences in otolith measurements and gill raker counts between the two major spawning stocks of hoki (Macruronus novaezelandiae) in new Zealand. N.Z. Fish. Assess. Rep. 2003/7, 23 p. Minist. Fish., Wellington, New Zealand.

Hicks, A. C., C. Wetzel, and J. Harms.

2014. The status of rougheye rockfish (Sebastes aleutianus) and blackspotted rockfish (S. melanostictus) as a complex along the U.S. West Coast in 2013, 250 p. Pac.
Fish. Manage. Counc., Portland, OR. [Available from website.]

Hutchinson, C. E., C. R. Kastelle, D. K. Kimura, and D. R. Gunderson.

2007. Using radiometric ages to develop conventional aging methods from shortraker rockfish (Sebastes borealis). In Biology, assessment, and management of North Pacific rockfishes. Alaska Sea Grant Rep. AK-SG-07-01 (J. Heifetz, J. DiCosimo, A. J. Gharrett, M. S. Love, V. M. O'Connell, and R. D. Stanley, eds.), p. 237-249. Alaska Sea Grant Coll. Program, Univ. Alaska Fairbanks, Fairbanks, AK

Hyde, J. D., C. A. Kimbrell, J. E. Budrick, E. A. Lynn, and R. D. Vetter.

2008. Cryptic speciation in the vermilion rockfish (Sebastes miniatus) and the role of bathymetry in the speciation process. Mol. Ecol. 17:1122-1136. Crossref

Jordan, D. S., and B. W. Evermann.

1898. The fishes of North and Middle America: a descriptive catalogue of the species of fish-like vertebrates found in the waters of North America, north of the Isthmus of Panama. Part II. Bull. U.S. Natl. Mus. 47:1241-2183.

Kanayama, T., and D. Kitigawa.

1982. Fishes in Iwate Prefecture Soi-Menukerui, 47 p. Iwate Fish. Exp. Stn., Iwate, Japan.

Kastelle, C. R., D. K. Kimura, and B. J. Goetz.

2008. Bomb radiocarbon age validation of Pacific ocean perch (Sebastes alutus) using new statistical methods. Can. J. Fish. Aquat. Sci. 65:1101-1112. Crossref

Lleonart, J., J. Salat, and G. J. Torres.

2000. Removing allometric effects of body size in morphological analysis. J. Theor. Biol. 205:85-93. Crossref

Love, M. S., M. M. Yoklavich, and L. K. Thorsteinson.

2002. The rockfishes of the northeast Pacific, 405 p. Univ. Calif. Press, Berkeley, CA.

Matsubara, K.

1934. Studies on the scorpaenoid fishes of Japan. I. Descriptions of one new genus and five new species. J. Imperial Fish. Inst. 30:199-210.

Matta, M. E., and D. K. Kimura.

2012. Age determination manual of the Alaska Fisheries Science Center Age and Growth Program. NOAA Prof. Pap. NMFS 13, $92 \mathrm{p}$.

McCullagh, P., and J. A. Nelder.

1989. Generalized linear models, 526 p. Chapman and Hall, New York.

Ormseth, O. A., and P. D. Spencer.

2011. An assessment of vulnerability in Alaska groundfish. Fish. Res. 112:127-133. Crossref

Orr, J. W., and S. Hawkins.

2008. Species of the rougheye rockfish complex: resurrection of Sebastes melanostictus (Matsubara, 1934) and a redescription of Sebastes aleutianus (Jordan and Evermann, 1898) (Teleostei: Scorpaeniformes). Fish. Bull. 106:111-134.

$\mathrm{R}$ Core Team.

2017. R: a language and environment for statistical computing. R Foundation for Statistical Computing, Vienna, Austria. [Available from website, accessed March 2017.]

Sadighzadeh, Z., V. M. Tuset, T. Valinassab, M. R. Dadpour, and A. Lombarte.

2012. Comparison of different otolith shape descriptors and morphometrics for the identification of closely related species of Lutjanus spp. from the Persian Gulf. Mar. Biol. Res. 8:802-814. Crossref 
Seeb, L. W.

1986. Biochemical systematics and evolution of the Scorpaenid genus Sebastes. Ph.D. diss., 176 p. Univ. Wash., Seattle, WA.

Shotwell, S. K., D. H. Hanselman, and J. Heifetz.

2017. Assessment of the rougheye and blackspotted rockfish stock complex in the Gulf of Alaska. In Stock assessment and fishery evaluation report for the groundfish resources of the Gulf of Alaska, p. 1055-1148. N. Pac. Fish. Manage. Counc., Anchorage, AK. [Available from website.]
Tuset, V. M., A. Lombarte, J. A. Gonzalez, J. F. Pertusa, and M. J. Lorente.

2003. Comparative morphology of the sagittal otolith in Serranus spp. J. Fish Biol. 63:1491-1504. Crossref von Bertalanffy, L.

1938. A quantitative theory of organic growth (inquiries on growth laws. II). Hum. Biol. 10:181-243.

Wimberger, P., J. Burr, A. Gray, A. López, and P. Bentzen.

1999. Isolation and characterization of twelve microsatellite loci for rockfish (Sebastes). Mar. Biotechnol. 1:311-315. Crossref 